\title{
A INSTRUMENTAÇÃO CIRÚRGICA NA FORMAÇÃO DO ENFERMEIRO*
}

\author{
Maria do Carmo Querido Avelar** \\ Kazuko Uchikawa Graziano* ** \\ Arlete Silva***
}

\begin{abstract}
RESUMO - Descrever a experiência da prática da instrumentação cirúrgica relatada por dois grupos de alunos do curso de Graduação em Enfermagem, identificar os aspectos favoráveis e desfavoráveis da experiência vivenciada e obter subsídios para o melhor desenvolvimento do processo ensino-aprendizagem. Os alunos foram convidados a relatar suas experiências frente à prática da instrumentação cirúrgica, no final do estágio da disciplina Enfermagem em Centro Cirúrgico.
\end{abstract}

RESUMO - Descreve a experiência da prática da instrumentação cirúrgica relatada por dois grupos de alunos do curso de Graduação em Enfermagem, para identificar os aspectos favoráveis e desfavoráveis da experiência vivenciada e obter subsídios para o melhor desenvolvimento do processo ensino-aprendizagem. Os alunos foram convidados a relatar suas experiências frente à prática da instrumentação cirúrgica, no final do estágio da disciplina Enfermagem em Centro Cirúrgico.

\section{INTRODUÇÃO}

A prática da instrumentação cirúrgica deixada de ser realizada como parte do estágio em Centro Cirúrgico (CC), pela maioria das escolas de enfermagem, passou a ser uma das preocupações dos enfermeiros de $\mathrm{CC}$, cujo intento seria resgatar a responsabilidade delegada a agentes de enfermagem ou não, como a maioria dos instrumentadores cirúrgicos, cujas atividades estão assumindo uma abrangência que engloba tarefas e procedmentos que são próprios da atuação da equipe de enfermagem.

O Decreto no 94.406 de 08/06/87 deixa expressa a atividade de instrumentar, quando necessário, como atribuição dos elementos da equipe de enfermagem, espcif icamente ao auxiliar de enfermagem (BRASIL, 1987).

A preocupação dos órgãos de enfermagem diante das tentativas de profissionalização do instrumentador cirúrgico, bem com sua luta na manutenção de seus espaços, manifesta-se de modo contínuo na sua constante tarefa de disciplinar as atribuições dos seus profissionais e ocupacionais.

O Projeto de Lei de 15/09/86 que dispõe sobre o exercício da profissão do instrumentador cirúrgico, em seu artigo 10, parágrafo único, propõe seja o "instrumentador cirúrgico aquele profissional de nível médio que ordena e controla o instrumento" antes, durante e após a intervenção cirúrgica, fornecendo-o ao cirurgião, zelando pela assepsia do ato.

O Conselho Federal de Enfermagem (COFEn), através de sua Procuradoria Jurídica, enviou seu Parecer sobre o referido Projeto que intenta regulamentar o exercício profissional do instrumentador cirúrgico e recomenda a lutą contínua na detenção dos esforços para tal, de forma a manter a instrumentação cirúrgica dentro das ocupações da enfermagem (CONSEL HO FEDERAL DE ENFERMAGEM).

A reivindicação dos alunos matriculados na disci- plina Enfermgem em Centro Cirúrgico da Escola de Enfermagem da USP, da possibilidade da prática da instrumentação cirúrgica, complementando os aspectos teóricos, desencadeou uma série de situações que favoreceram a reintrodução da mesma.

A experiência prática da instrumentação cirúrgi ca, no conteúdo programático da disciplina Enfermagem em Centro Cirúrgico da EEUSP, foi oferecida até o ano de 1972 quando então foi gradativamente retirada, por ser considerada altamente estressante para o aluno.

Atualmente, esta disciplina com carga horária teórica de 270 horas, sendo 120 horas de teoria e 150 de prática, abrange as áreas de centro cirúrgico (CC), recuperação anestésica e centro de material, oportunizando o desenvolvimento da assistência de enfermagem perioperatória e demais atividades inerentes aos procedimentos anestésico-cirúrgicos.

A prática da instrumentação cirúrgica foi reinserida tendo em conta as reivindicações dos alunos, as solicitações de vários enfermeiros assistenciais, atuantes em $\mathrm{CC}$, de curso de instrumentação cirúrgica e também os aspectos referentes à legislação do exercício profissional da enfermagem, que atribui a atividade de instrumentador, quando necessário, ao auxiliar de enfermagem, onde a responsabilidade de seu preparo e treinamento é da competência do enfermeiro.

No final do estágio desta disciplina, o aluno foi convidado a relatar as suas percepções frente à prática de instrumentação cirúrgica. Para tanto, foi utilizada a entrevista não diretiva, com uso de gravador. Os dados obtidos possibilitaram uma visão sobre $\cdot o$ que há de comum na percepção dos alunos em relação à essa prática, trabalhando com as variáveis que emergiram ao longo do estudo, assim como as questões e hipóteses que explicaram essa realidade.

Neste estudo, propusemo-nos a descrever a experiência da prática da instrumentação cirúrgica relatada por dois grupos de alunos do curso de Graduação

* Trabalho classificado em 3ํ lugar-Prêmio Lais Neto dos Reis - 40 CBEn-Belém.

** Professor Assistente do Departamento de Enfermagem Médico-Cirúrgica da Escola de Enfermagem-USP.

*** Auxiliar de Ensino do Departamento de enfermagem Médico-Cirúrgico da Escola de Enfermagem-USP 
"em Enfermagem da EEUSP, no final do estágio da disciplina Enfermagem em Centro Cirúrgico da EEUSP.

\section{OBJETIVOS}

O presente estudo tem como objetivos:

- analisar a experiência dos alunos na prática de instrumentação cirúrgica, durante o desenvolvimento da disciplina Enfermagem em Centro Cirúrgico;

- identificar aspectos favoráveis e desfavoráveis da experiência vivenciada, bem com a importância atribuída à prática da instrumentação cirúrgica, relatada pelo aluno matriculado;

- obter subsídios para o melhor desenvolvimento do processo ensino-aprendizagem da disciplina ECC.

\section{MATERIAL E MÉTODO}

\section{População}

A população foi formada por dois grupos de alunos - GRUPO I e GRUPO II - matriculados no 5o semestre do Curso de Graduação da EEUSP, que cursaram a disciplina Enfermagem em Centro Cirúrgico.

O GRUPO I contou com $22(78,5 \%)$ alunos e o GR UPO II com 26 (91\%), totalizando 46 alunos, ou seja, $85 \%$ dos matriculados na disciplina ECC.

O GRUPO I cursou a disciplina no período de março-abril de 1988 e o GRUPO II em maio junho do mesmo ano.

\section{Seleção da amostra}

A amostra contou de alunos que haviam terminado o estágio realizado no CC do Hospital Universitário da USP, durante o desenvolvimento do conteúdo pro . gramático da disciplina ECC, onde tiveram a oportunidade de realizar a prática da instrumentação cirúrgica, tendo ou não experiência anterior nessa prática.

\section{Coleta de dados}

Para a coleta de dados foi utilizada a técnica de entrevista não diretiva, marcada previamente com o aluno, utilizando o gravador.

As entrevistas foram iniciadas com a formulação de uma questão sobre o significado da experiência da instrumentação cirúrgica.

O tempo de duração da entrevista não foi determinado, tendo cada entrevista a duração média de 20 minutos.

\section{Análise dos dados}

As entrevistas, gravadas, foram transcritas e, posteriormente, devolvidas aos alunos para a sua validação. Após a validação, os dados foram agrupados segundo sua pertinência e analisados em números absolutos e percentuais.

Através do estudo podemos identificar que o hospital onde o aluno teve mais oportunidade de ins- trumentar, em ambos os grupos, foi o Hospital Universitário da USP. A prática da instrumentação cirúrgica no referido hospital é atualmente executada por acadêmicos de medicina que não se opuseram em ceder essa oportunidade ao aluno de enfermagem. A existência de uma filosofia de integração docente-assistencial entre o Departamento de Enfermagem do HU-USP e a EE-USP, sem dúvida, muito ajudou na receptividade dos alunos de enfermagem no campo de estágio. $\mathrm{O}$ movimento cirúrgico pequeno (em média 6 cirurgias diárias) permitiu ao aluno melhor entrosamento com a equipe cirúrgica e de enfermagem e a possibilidade de atuação planejada fez do HU-USP, o local mais oportuno para a prática da instrumentação cirúrgica.

Nos outros capos de estágio, muitas vezes, a equipe cirúrgica constituía-se de elementos fixos o que dificultava ao aluno a obtenção de oportunidade de instrumentar. Outro impedimento foi a necessidade de um instrumentador habilitado para que a extensa programação diária (em média 60 cirurgias) pudesse ser cumprida. A falta de valorização do aluno de enfermagem na prática da instrumentação cirúrgica foi apontada, em alguns de seus depoimentos, como motivo para que não tivesse procurado oportunidades de instrumentar nos referidos hospitais.

Decorrente das condições e do tempo destinado à realização da prática da instrumentação, constatamos, pelos relatos dos alunos, que $21(45,7 \%)$ deles tiveram a oportunidade de instrumentar 2 (duas) vezes, sendo que $32 \%$ referiram ser esse número de experiências suficiente para assimilação básica do procedimento, embora não haja condições de desenvolver destreza; $18 \%$ acharam insuficiente e, portanto, gostariam de ter mais oportunidades, e 50\% não fizeram referência sobre este dado.

Consideramos que a intenção básica da disciplina foi of erecer embasamento mínimo e não a destreza decorrente da repetição da prática da instrumentação, porquanto o tempo e as oportunidades previstas eram sabidamente limitadas.

Devido a exigüidade do tempo de permanência do aluno no campo de estágio, $46 \%$ das oportunidades que tiveram para instrumentar foram consideradas situações complexas devido ao porte da cirurgia (de médio para grande porte), não havendo escolha e devendo adaptar-se às condições do momento presente.

A primeira oportunidade de realizar a prática da instrumentação cirúrgica foi relatada como uma experiência inicialmente estressante, com sentimento de insegurança, receio e medo do desconhecido. No entanto, com o transcorrer da mesma, foi amenizado o grau de ansiedade até desmistificar a referida prática como um desempenho extremanente difícil.

Embora fosse referido maior positividade da segunda experiência em relação a primeira, foi declarado não terem sido, estas duas experiências, suficientes para eliminar totalmente o sentimento de insegurança.

Intercorrências inesperadas inerentes ao comportamento e particularidades dos elementos da equipe cirúrgica fora indicados como fatores mais estressantes do que propriamente a falta de segurança que a repetição da prática poderia conferir.

A maioria dos alunos $(72 \%)$ fizeram referência à receptividade da equipe cirúrgica associada ao sucesso de suas experiências, por diminuirem a insegurança em que se encontrava nesta fase inicial. Expressaram-se 
assim: "a tranqüilidade na prática da instrumentação cirúrgica foi conseqüência da compreensão, ajuda, atenção e paciência dos elementos da equipe cirúrgica; a disponibilidade para ensinar os detalhes dos aspectos principais do ato cirúrgico, os elogios facilitaram e motivaram a realização da prática, provocando descontração".

Por outro lado, percebemos que a solicitação da equipe cirúrgica para os alunos participarem das cirurgias como instrumentadores, predispõe a um trabalho de cooperação, integração, assumindo corajosamente com a equipe riscos e estresses próprios do momento; ao contário, quando os elementos estavam por demais estressados e agressivos, fazendo exigências de um desempenho mais acurado, o aluno vacila, se atrapalha aumentando o nível de estresse e tornando a experiência negativa.

A maioria dos alunos $(89,1 \%)$ considerou importante a experiência da prática da instrumentaçăo cirúrgica integrando o conteúdo programático da disciplina ECC.

A seguir, são colocadas resumidamente, algumas das justificativas apresentadas:

- a prática da instrumentação cirúrgica proporciona noção mais precisa dos conhecimentos teóricos das disciplinas básicas (anatomia, fisiologia, fisiopatologia...), visualizados no campo operatório;

- a abordagem do paciente na entrevista da visita pós operatória se torna mais fácil e segura, na medida que se conhece as eventuais intercorrências da fase intra-operatória correlacionando-as com os possíveis problemas identificados;

- produz, também, um sentimento de maior utilidade, ajuda e participação, estreitando o relacionamento com o paciente, propiciando uma visão mais global do mesmo;

- reforça os princípios de assepsia, conhece melhor o instrumental cirúrgico, bem como sua utilidade imediata e ajuda na assimilação e compreensão dos rituais estéreis;

- facilita o estabelecimento de rápida interação da equipe cirúrgica com o circulante de S.O. e demais elementos da equipe de enf ermagem.

Os $10(21,7 \%)$ alunos que consideraram ser a instrumentação cirúrgica uma opção de trabalho para o enfermeiro, mencionaram sua formação científica bem como seu nível de preparo técnico mais apropriado para desenvolver essa atividade como elemento da equipe cirúrgica.

Outro aspecto favorável seria a desmistificação da prática da instrumentação cirúrgica, constituindo um campo novo de atuação, encorajando a enfermagem a assumir o seu espaço, assegurando que o procedimento seja realizado por elemento da equipe de enfermagem, profissionalizado, sob a supervisão e controle da enfermeira.

Os que não consideraram a instrumentação cirúrgica como opção de trabalho para a enfermeira, expressaram a perda do potencial do profissional em uma prática muito restrita, mecanizada, qưe não exige ca- pacitação profissional, considerando a diversidade de funções a ela impostas no CC.

A posição técnico-administrativa e gerencial da enfermeira, derivadas do seu desempenho rotineiro, deixa clara a idéia da sua atuação nesta área com o objetivo de ensino, supervisão, controle e seleção de recursos humanos para a referida prática.

Essas considerações coadunam-se aos aspectos legais do exercício profissional, onde o enfermeiro torna-se responsável pelo treinamento do pessoal auxiliar.

A importância da prática da instrumentação cirúrgica fundamenta-se nas seguintes afirmações: a prática da instrumentação cirúrgica dentro da visão mais abrangente, da sistemática de assistência perioperatória, constitui um elo de ligação entre assistência de enfermagem nos períodos pré, trans, intra e pósoperatório, conduz a uma visão globalizada das funções exercidas pelos elementos da equipe de enfermagem na sala de operações, incentiva o desenvolvimento do estágio, ajuda a assimilar e compreender melhor as demais disciplinas permite visualizar a interrelação da instrumentação cirúrgica com os procedimentos desenvolvidos em centro cirúrgico e centro de material.

Como podemos observar, um aspecto importante mencionado foi a conexão da instrumentação cirúrgica com a Sistemática de Assistência Perioperatória (SAEP), cuja noção de complementaridade permite uma assistência individualizada, contínua, planejada e integral do paciente.

Consideraram indispensáveis os conhecimentos e a prática da instrumentação cirúrgica na formação básica do enfermeiro para poder ensinar, conhecer me lhor esta prática e atuar em situações de emergência.

\section{Aspectos sobre avaliação do curso e sugestões}

A possibilidade do atendimento das reinvidicações dos alunos levou-os a encararem esta experiência de modo mais agradável e positivo.

Foi ressaltado nos pronunciamentos dos alunos a importância da aula de simulação da instrumentação cirúrgica, conquanto seja um método que reduz a ansiedade e o estresse da primeira experiência.

O conteúdo teórico foi julgado satisfatório pela maioria dos alunos, embora alguns tenham considerado insuficiente, levando-nos a entender as necessidades de cada aluno.

A possibilidade da utilização do laboratório de enfermagem desta Escola de Enfermagem, para exercitar alguns procedimentos, foi dificultada devido à falta de conciliação de horário das monitoras, que dão suporte ao treinamento, e o tempo livre dos alunos nos intervalos das aulas, somados à necessidade de se dispor de instrumentais especiais não constante nas caixas básicas disponíveis para estudo.

Outro ponto conflitante, mencionado, foi a exigüidade do tempo compreendido entre a determinação da cirurgia que o aluno iria instrumentar e a possibilidade de revisão do conteúdo da caixa de instrumental a ser usada no ato cirúrgico.

Em vista disso, os alunos sugeriram que o estágio em Centro de material sempre antecedesse o estágio em S.O.

Embora a maioria (56\%) dos alunos não tenha mencionado, $33 \%$ deles declararam que o tempo pre- 
visto para a realização da prática da instrumentação foi muito curto, mesmo considerando que as experiências vivenciadas foram complexas, ricas e intensas.

\section{CONCLUSÕES}

Este trabalho permitiu-nos analisar as experiên cias dos alunos na prática da instrumentação cirúrgica realizada no decorrer do estágio da disciplina Enfermagem em Centro Cirúrgico.

A análise dos dados mostrou-nos pontos bastante favoráveis dessa experiência, sobretudo quanto à importância da sua integração nesse estágio.

Pontos desfavoráveis foram mencionados, sendo o de maior freqüência a exigüidade do tempo para treinamento em laboratório, dificuldade de revisar os instrumentais antes da prática da instrumentação cirúrgica, bem como o estágio em centro de material realizado posteriormente ao de centro cirúrgico.

Com isso concluímos ter sido o presente estudo altamente positivo, fornecendo-nos evidências da necessidade de manutenção da prática da instrumentação cirúrgica na disciplina Enfermagem em Centro Cirúrgico.

\section{CONSIDERAÇÕES FINAIS}

O presente trabalho levou-nos a crer, docentes da disciplina Enfermagem em Centro Cirúrgico da EEUSP, que a instrumentação cirúrgica constitui-se numa prática importante na formação do enfermeiro, uma vez que a análise dos dados decorrentes das afirmações dos alunos possibilitaram uma visão sobre o que há de comum nas suas percepções.

Ambos os grupos, e de modo individualizado, tiveram a oportunidade de expressar livremente suas percepções sobre a experiência da prática da instrumentação cirúrgica, propiciando a obtenção de uma gama de dados bastante profícuos e críticos.

Os alunos relataram ser a enfermeira o profissio nal mais adequado para desempenhar a prática da instrumentação cirúrgica, considerando a sua formação profissional.

A contribuição em informações e elementos disponíveis neste relato, confere o nosso compromisso em fornecer subsídios que assegurem o desenvolvimento do processo ensino-aprendizagem com vistas à elevação da qualidade da formação do profissional de enfermagem.

\section{REFERÊNCIAS BIBLIOGRÁFICAS}

1 BRASIL, Leis, Decretos, tc. Demeto no 94.406 de 08/06/1987. Diário Oficial. Brasília, 09 de junho de 1987. p. 8853-55.

2 CIAMPONE, M.H.T. Administração participativa: análise de uma experiência vivenciada por um grupo, na prática da enfermagem hospitalar. In: ENCONTRO INTERAMERICANO DE PESQUISA QUALITATIVA EM ENFERMAGEM, 1, São Paulo, 22-26 fev. 1988. Anais... p. 117-123.

3 CONSELHO FEDERAL DE ENFERMAGEM. Procuradoria Jurídica. Parecer $n^{\circ}$ 34/86. Exame de projeto de lei.

4 LDKE, M. \& ANDRE, M.E.D.A. Pesquisa em educação: abordagens qualitativas. São Paulo, EPU, 1986. 98 p.

5 SILVA, A., GRAZIANO, K.U., AVELAR, M.C.Q. O significado da experiência da instrumentação cirúrgica para os alunos do curso de graduação em enfermagem. In: JORNADA DE ENFERMAGEM EM CENTRO CIRÚRGICO DO ESTADO DE SÃO PAULO, 2, São Paulo, 4-6 jul. 1988. 14 p. mimeogr. 